\title{
Preparation and Biodegradation of Nanocellulose Reinforced Polyvinyl Alcohol Blend Films in Bioenvironmental Media
}

\author{
Nusaiba Islam ${ }^{1}$, Sharmin Jahan Proma ${ }^{1}$, Ashiqur Rahman ${ }^{1,2^{*}}$ \\ and Ashok Kumar Chakraborty ${ }^{1}$ \\ ${ }^{1}$ Nanomaterials Laboratory, Department of Applied Chemistry and Chemical Engineering, \\ Islamic University, Kushtia-7003, Bangladesh. \\ ${ }^{2}$ Department of Chemical Engineering, Faculty of Engineering and Built Environment, School of \\ Engineering, The University of Newcastle, Callaghan, New South Wales 2308, Australia.
}

\section{Authors' contributions}

This work was carried out in collaboration between all authors. Author NI designed the study, performed the statistical analysis, wrote the protocol and wrote the first draft of the manuscript. Authors SJP and AR managed the analyses of the study. Author AKC managed the literature searches. All authors read and approved the final manuscript.

Article Information

DOI: $10.9734 / C S J I / 2017 / 32570$

Editor(s):

(1) Zygadlo Julio Alberto, Professor of Chemistry, National University of Cordoba, Argentina.

Reviewers:

(1) Jiulong Xie, Louisiana State University, USA. (2) Mona Nassar, National Research Centre, Egypt. (3) Luo, Ching-Ruey (Edward), National Chi-nan University, Taiwan. Complete Peer review History: http://www.sciencedomain.org/review-history/19524

Original Research Article

Received $2^{\text {nd }}$ March 2017

Accepted $9^{\text {th }}$ June 2017

Published 14 ${ }^{\text {th }}$ June 2017

\begin{abstract}
Solution casting method was used to prepare nanocellulose reinforced polyvinyl alcohol (PVOH) from Oil palm empty fruit bunches. Different environmental test were used to investigate the biodegradability of the composite in soil and compost as well as in water and acidic solution. The morphology of the composite was investigated by scanning electron microscopy. The composite film with nanocellulose and without nanocellulose were compared, nanocellulose modified PVOH film showed more highly degradable by soil and compost as well as in enzymes. From the biodegradation study it was observed that the rate of degradation of the composite depend on the nanocellulose content. Surface morphology study of the composite exposed the distribution of nanocellulose in the PVOH.
\end{abstract}


Keywords: Biodegradation; nanocellulose; $\mathrm{PVOH}$; environmentally friendly; enzyme degradation.

\section{INTRODUCTION}

Now a day the effect of synthetic polymer materials has become an environmental issue. These materials take more than thousand years to decompose in soil, which is the major part of environmental pollution [1]. Nowadays, biopolymers have drawn more and more interest because of increasing environmental concern and decreasing fossil resources. This evolution motivates academic and industrial researchers to develop novel materials labelled as "environmentally- friendly", i.e., materials produced from alternative resources, with lower energy consumption, biodegradability and nontoxicity [2]. Depending on the raw material the environmental friendly polymer materials divided into two groups: Synthetic degradable polymers and natural renewable polymers. Chitosan, cellulose and starch are the sources of natural renewable polymers. Since biopolymers are biodegradable and the main products are obtained from renewable resources such as agro resources, they represent an interesting alternative route to common nondegradable polymers for short-life range applications (packaging, agriculture, biomedical etc.). Nevertheless, until now, some of the biopolymers (e.g. polylactic acid, which is fully biodegradable) are costly compared to conventional thermoplastic and they are sometimes too weak for practical use. Therefore, it appears necessary to extend the search for fully biodegradable polymers, which are economically accessible and industrially accepted [3]. Composites are novel materials with drastically improved properties due to the incorporation of small amounts (less than 10 wt. \%) of nano-sized fillers into a polymer matrix. They offer high surface area, more than $200 \mathrm{~m}^{2} / g$, i.e., a huge interface with the polymer (matrix), which governs the material properties [4]. The final behavior can be considerably improved by the strong and extensive polymernano filler interactions, as well as, good particle dispersion [4]. In tune with the current environmental concerns, the researchers are interested in biocomposites area, which is a solution for various industrial as well as ecological problems. Moreover, since industry is concerned with sustainable developments, the production cost of biocomposites goes on decreasing, which will allow strong developments of biopolymers-based materials [3]. Biocomposites are obtained by adding nanofillers to biopolymers, resulting in very promising materials since they show improved properties with preservation of the material biodegradability, without eco-toxicity. These materials are mainly destined for biomedical applications and different short-term applications, e.g., packaging, agriculture or hygiene devices. They thus represent a strong and emerging answer for improved and eco-friendly materials.

A necessary pre-requisite for extending their utilization is their biodegradability in natural environments, where they may serve as a source of carbon and energy for a variety of microorganisms [5]. Biodegradation studies are usually carried out in soil or compost. In particular, enhanced biodegradation of these materials may occur in the presence of compost, a complex biological environment, in which microbial diversity is relatively high and where there is an increased degradation potential [6]. According to ISO, CEN definition [7], biodegradation is the degradation caused by biological activity, especially by enzymatic action, leading to a significant change in the chemical structure of the exposed material and resulting in the production of carbon dioxide, water, mineral salts (mineralization) and new microbial cellular constituents (biomass) [8].

In the present paper, biocomposites prepared by reinforcing nanocellulose in a matrix of polyvinyl alcohol $(\mathrm{PVOH})$ is discussed. The nanocellulose is isolated from oil palm empty fruit bunches (OPEFB) which is a renewable resource [9]. It is not only biodegradable but also biocompatible [10]. In the present study, nanocellulose was incorporated into the PVOH matrix, which further facilitated the degradation process.

\section{MATERIALS AND METHODS}

Poly (vinyl alcohol) (Kuraray PVA-220S) was obtained from Kuraray Co., Ltd. (Singapore). Oil palm empty fruit bunch (OPEFB) fibers were purchased from Sabutek Sdn. Bhd., Malaysia. OPEFB underwent a sieving process to obtain fiber particles in the range of 4 to $6 \mathrm{~mm}$. The fiber particles were then sent for grinding and sieving to obtain powder with diameter size between 100 and $150 \mu \mathrm{m}$. Hydrogen peroxide and formic acid were obtained from Fisher Scientific (USA). All other solvents and chemicals (analytical grade) were used as received [1]. 


\subsection{Pretreatment of OPEFB Fibers}

OPEFB fibers were first washed several times with $1.0 \mathrm{wt} \%$ washing detergent to remove all the contamination and dirt. Next, the OPEFB raw fiber was dried in an oven (SOV $70 \mathrm{~B}$, Thermoline) at $100 \pm 2^{\circ} \mathrm{C}$ until constant weight was achieved. The fiber was then dewaxed with ethanol $(70 \% \quad \mathrm{v} / \mathrm{v})$ using a Soxhlet apparatus (Favorit) for $6 \mathrm{~h}$. This step was followed by washing the dewaxed fibers with distilled water to remove the traces of alcohol. Later, the dewaxed fibers were suspended in a mixture of $100 \mathrm{~mL}$ of $10 \% \mathrm{NaOH}$ and $100 \mathrm{~mL}$ of $10 \% \mathrm{H}_{2} \mathrm{O}_{2}$. The mixture was autoclaved at 1.5 bar and $120^{\circ} \mathrm{C}$ for $1 \mathrm{~h}$. Finally, the fibers were separated from the dark brown supernatant and washed thoroughly with clean water [1].

\subsection{Extraction of OPEFB Nanocellulose}

During the extraction process, $5 \mathrm{gm}$ fiber were soaked in a mixture of $20 \%$ formic acid and $10 \%$ hydrogen peroxide, which was prepared in a 1:1 ratio $(\mathrm{v} / \mathrm{v})$. The mixture was placed in a water bath at $85^{\circ} \mathrm{C}$ for $2 \mathrm{~h} \mathrm{[1].}$

The delignified fibers were sent through a filtration process, and the samples were washed thoroughly with $10 \%$ formic acid prior to cleaning with distilled water. The extracted nanocellulose was light yellow in color. The nanocellulose was prepared as a suspension by re-suspending it in $10 \%$ hydrogen peroxide $(\mathrm{pH} 11)$ at $60^{\circ} \mathrm{C}$ for a duration of $90 \mathrm{~min}$. The nanocellulosic unit is shown in Fig. 1(a) and scanning probe microscopic (SPM) image of the nanocellulose in Fig. 1(b).

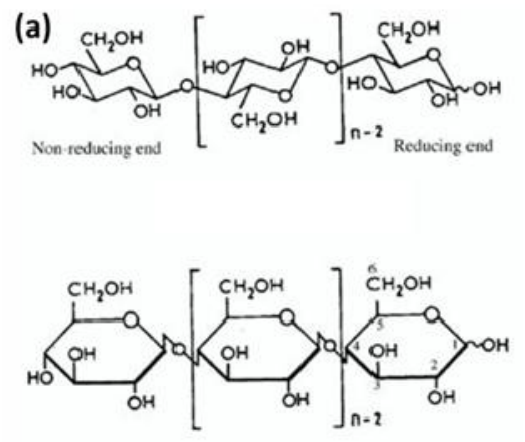

Fig. 1. (a): Nanocellulose unit.

\subsection{PVA/Nanocellulose Composite}

PVA-based composite films were prepared by the solution casting method. A $10 \mathrm{wt} \%$ aqueous solution of PVA was prepared by stirring at 1,000 rpm at room temperature to avoid clumps. Subsequently, the PVA solution was continuously stirred at $90^{\circ} \mathrm{C}$ for $2 \mathrm{~h}$, then sonicated for $5 \mathrm{~min}$. Various compositions of PVA/nanocellulose composites were prepared with a nanocellulose content ranging from 1 to 7 $w t \%$. The solutions were then poured into a mold and dried at room temperature for 7 days before being demolded. The thickness of the films was controlled to approximately $150 \mu \mathrm{m}$. The resulting thin composite films were then dried in an oven at $50^{\circ} \mathrm{C}$ for 1 day.

\subsection{Morphological Analysis}

The cross-section of the fractured surface morphology of the sample was examined by using a scanning electron microscope (Hitachi S$3400 N$, Thermo Scientific) with an accelerating voltage of $10 \mathrm{kV}$. The composite film was soaked in nitrogen liquid for 10 seconds. Then, the sample was fractured immediately to get a freeze-fractured surface. Before the SEM observation was done on the sample film, the cross-section surface of the fractured film was sputter-coated with a gold layer for $1 \mathrm{~h}$ to avoid electrostatic charging and poor image resolution.

\subsection{Enzymatic Testing}

An enzymatic mixture containing certain amounts of distilled water, $\alpha$-amylase and $\beta$-amylase were placed in a conical flask. The dried samples were cut into $3 \times 3 \mathrm{~cm}$ square specimens, and the

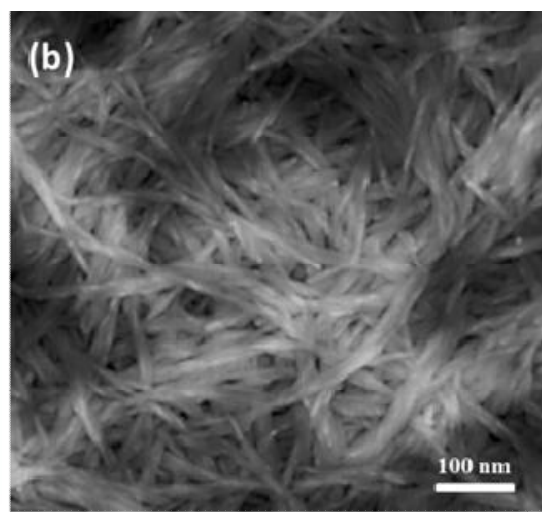

(b): SPM of nanocellulose 
samples were then weighed accurately using a digital balance and immersed in a conical flask. The flasks were placed in a shaking incubator at a rate of $120 \mathrm{rpm}$ for 60 hours at $30^{\circ} \mathrm{C}$. The samples were removed and rinsed with distilled water to remove the enzymatic mixture and dried in a desiccator under vacuum for 24 hours before being weighed and then the degree of enzymatic degradation [DED (\%)] was calculated.

\subsection{Soil Burial Test}

Two different pots were filled to their approximate capacity of $10 \mathrm{~L}$ with soil and compost. The samples were cut into $30 \times 50 \mathrm{~mm}$ pieces and buried in the soil at a depth of $10 \mathrm{~cm}$. The soil was placed in the laboratory, and the moisture of the soil was maintained by sprinkling water at regular time intervals. The excess water was drained through a hole at the bottom of the pot. The degradation of the samples was determined at regular time intervals ( 7 days) by carefully removing the sample from the soil and washing it gently with distilled water to remove soil from the film. The sample was dried under vacuum until a constant weight was obtained. Weight loss of the sample over time was used to indicate the degradation rate of the soil burial test.
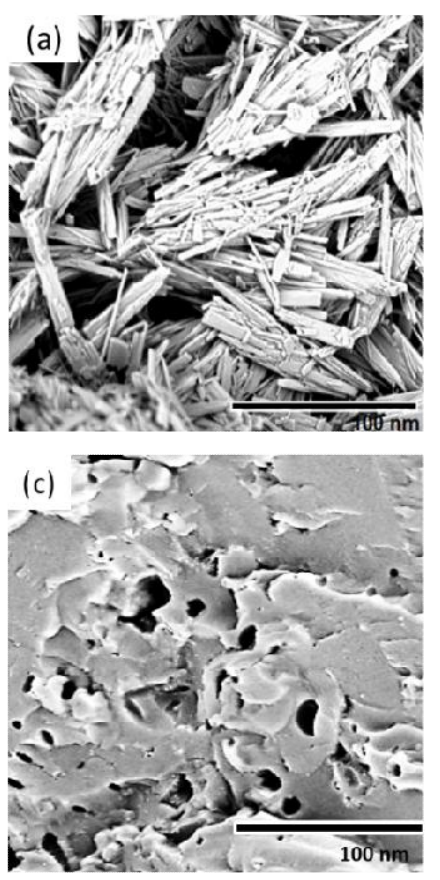

\subsection{Water Solubility Testing}

For the water solubility testing, the dried films were immersed in distilled water and an acidic solution made from $0.2 \mathrm{M} \mathrm{H}_{2} \mathrm{SO}_{4}$ at room temperature $\left(25^{\circ} \mathrm{C}\right)$. After equilibrium was reached (24 hours), the moisture on the surface of the film was removed and the weight of the film was measured. The swelled films were dried again for 24 hours at $60^{\circ} \mathrm{C}$.

\section{RESULTS AND DISCUSSION}

\subsection{Surface Morphological Study}

Fig. 2 shows the surface structure of pure $\mathrm{PVOH}$ and NCC modified PVOH composite films and Fig. 2(a) shows pure nanocellulose. During the casting method, the bubble trapped in the voids of the PVOH films. With the increase of the NCC content in the composite, the phase changed and the amorphous NCC finely dispersed with PVOH matrix. Cryo-fractured surface was caused for adding more than $70 \%$ of NCC and the surface became rougher and brittle. $\mathrm{PVOH}$ was finely distribute in the NCC matrix, but the NCC convinced remarkably at the same moment. After studying SEM micrograph, it is clear that $70 / 30$ $\mathrm{PVOH} / \mathrm{NCC}$ composite is suitable for the well dispersion of NCC in the matrix.
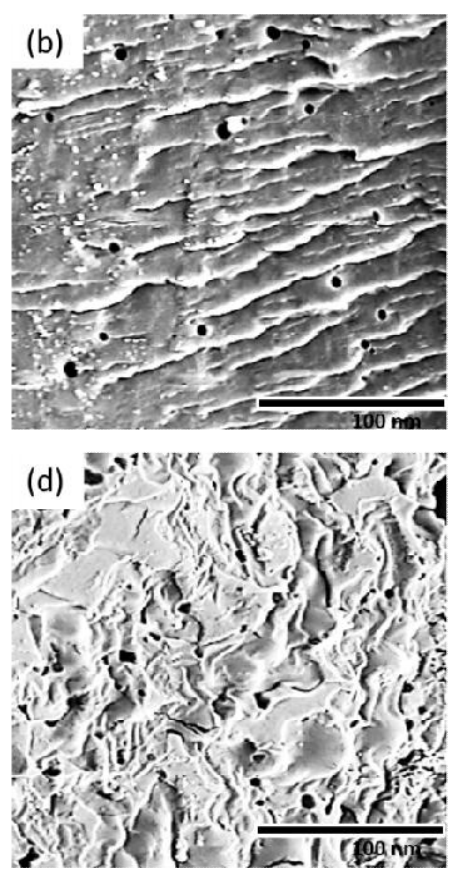

Fig. 2. SEM micrographs of (a) NCC, (b) PVOH/NCC, (c) 70/30 PVOH/NCC and (d) 30/70 $\mathrm{PVOH} / \mathrm{NCC}$ 


\subsection{Enzymatic Testing}

Fig. 3 shows the weight loss of the composite by enzyme degradation. The composites immersed in the enzyme media for 80 hours to observe the degradation rate. The graph represent that with increasing the cellulose content the rate of degradation also increase. Pure $\mathrm{PVOH}$ degradation rate was slower than the NCC modified PVOH composite. The 30/70 weight percent of PVOH/NCC showed higher degradation rate, which indicated $95 \%$ weight loss after 80 hours of insertion in the enzyme media. The NCC modified $\mathrm{PVOH}$ films can absorb more of the enzyme solution than pure $\mathrm{PVOH}$ because of the $-\mathrm{OH}$ groups of NCC that enhanced the absorption rate of enzyme in to the composite films [11]. With the increasing of NCC content in the composite, the enzyme absorption rate also increased.

\subsection{Soil Burial Test}

Figs. 4 and 5 show the weight loss of the composite in soil and compost. The composites buried in soil and compost for 10 weeks to observe the degradation rate. The graph represent that with increasing the cellulose content the rate of degradation also increase. Pure $\mathrm{PVOH}$ degradation rate was slower than the NCC modified PVOH composite. The 30/70 weight percent of $\mathrm{PVOH} / \mathrm{NCC}$ showed higher

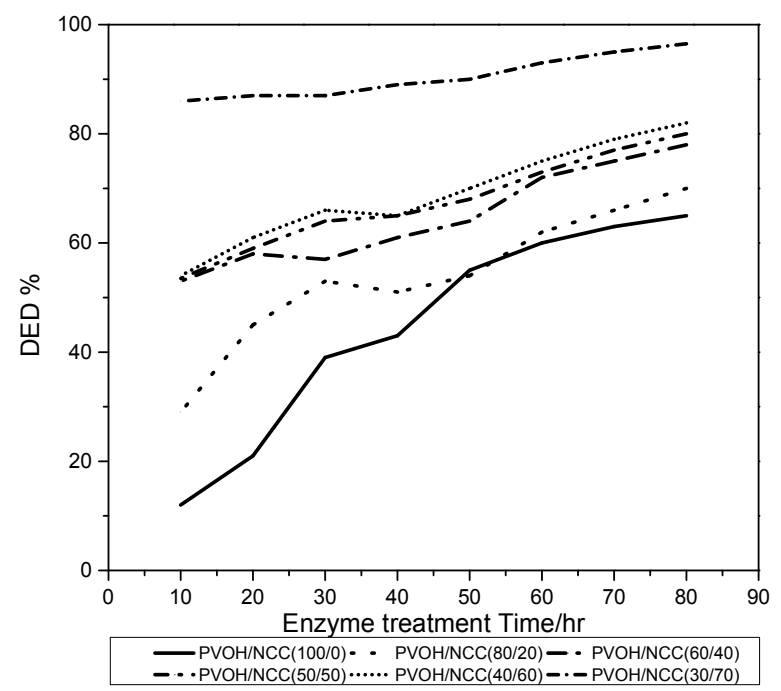

Fig. 3. Enzymatic degradation of PVOH (100/0) and PVOH/NCC films using $\alpha$ - and $\beta$-amylase

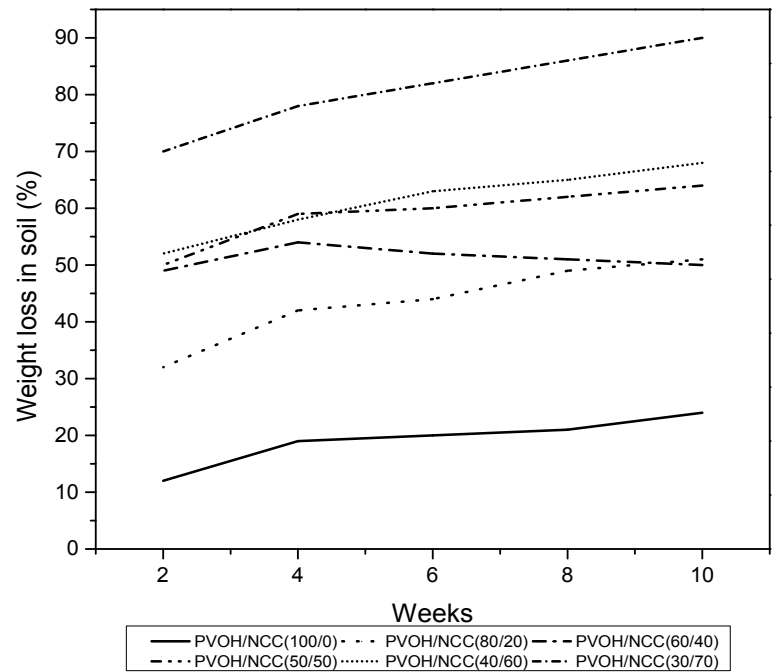

Fig. 4. Weight loss of PVOH/NCC films after 10 weeks in soil 


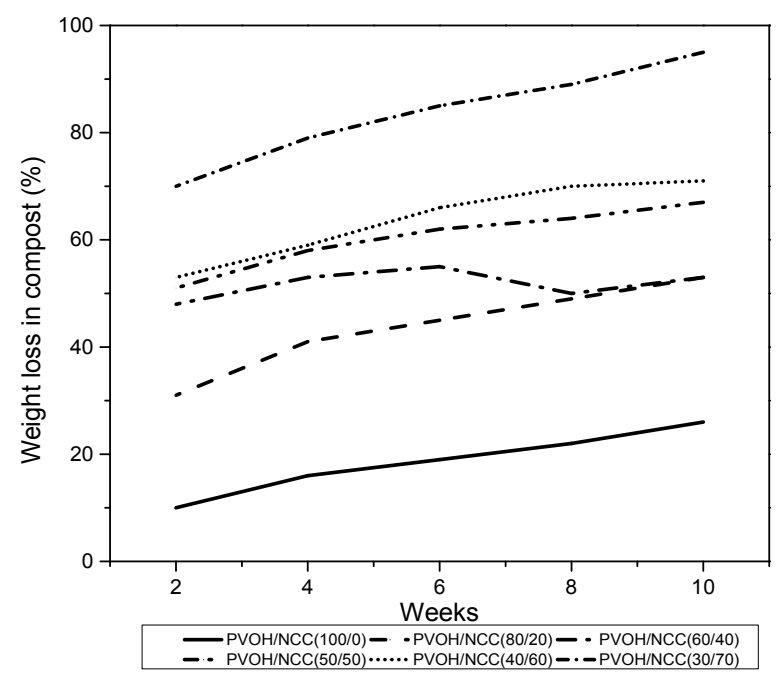

Fig. 5. Weight loss of PVOH/NCC films after 10 weeks in compost

degradation rate, which indicated $90 \%$ weight loss after 10 weeks of burial in soil and compost [12]. NCC is more biodegradable than PVOH. Biodegradation rate increase in compost than oil because compost usually made from organic compound. Generally, compost made from different kinds of plant and animal decomposition. For that reason the nutrients present in compost can degrade the NCC modified PVOH rapidly than in normal soil [10].

\subsection{Kinetic Studies of Water Absorption and Water Solubility Testing}

Figs. 6 and 7 show the moisture absorption rate of the composite in distilled water and in acidic media. The composites insertion in water and acid for 40 hours to observe the moisture absorption rate. The graph represent that with increasing the cellulose content the rate of moisture absorption also increase. Rate of moisture absorption for the pure $\mathrm{PVOH}$ was slower than the NCC modified PVOH composites. The 30/70 weight percent of $\mathrm{PVOH} / \mathrm{NCC}$ showed higher absorption rate, which indicated $140 \%$ moisture absorption after 40 hours of insertion in water and acidic media [13].

Fig. 8 shows the water solubility rate of the composite in distilled water and in acidic media. The graph represent that with increasing the

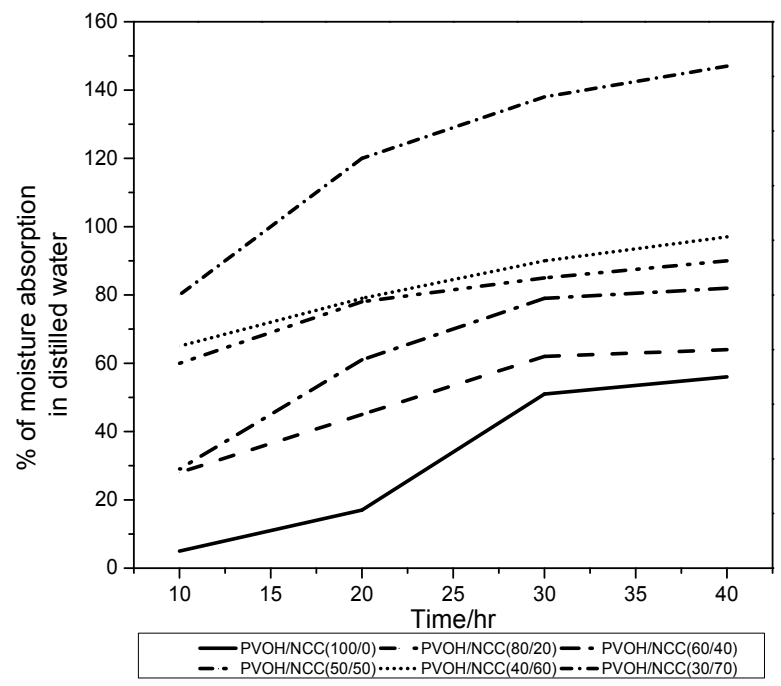

Fig. 6. Effect of nanocellulose on water uptake of PVOH composites in distilled water 


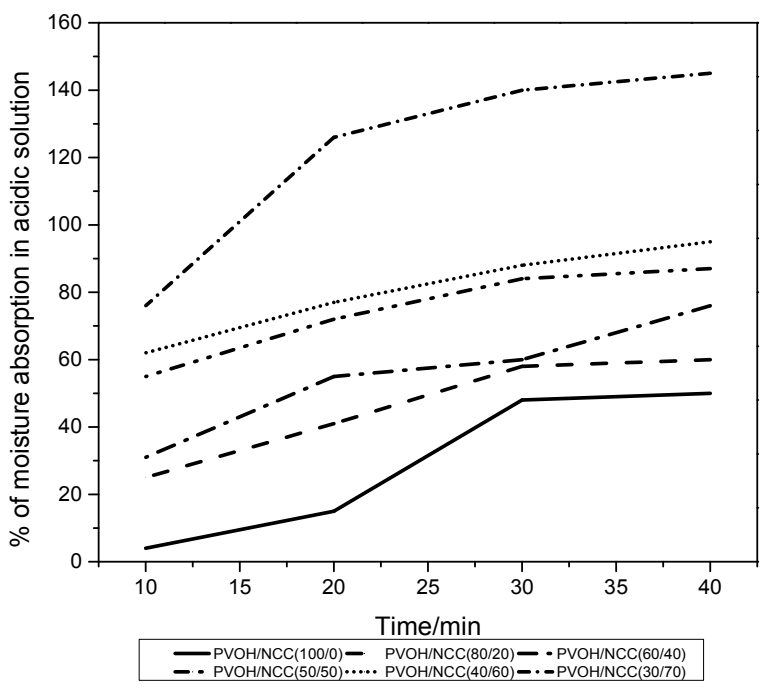

Fig. 7. Effect of nanocellulose on water uptake of PVOH composites in an acidic solution

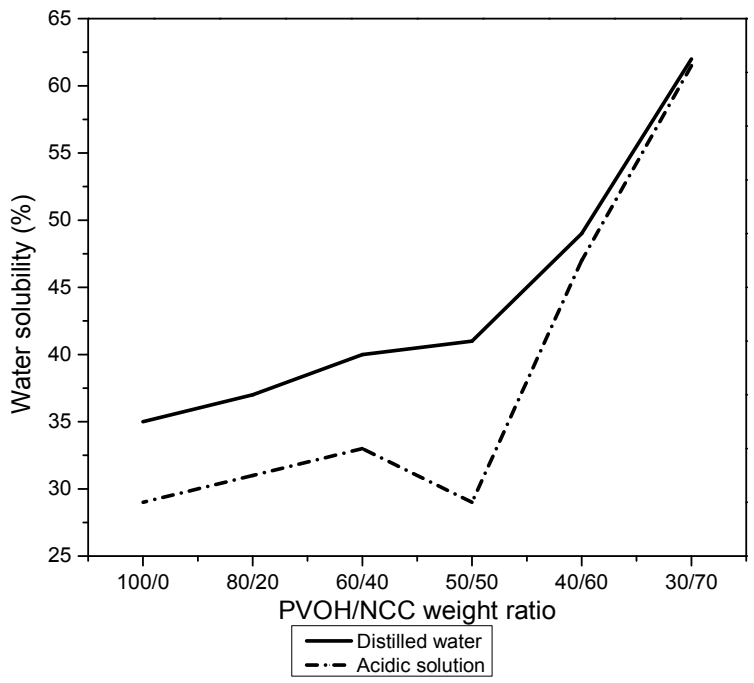

Fig. 8. Water solubility of PVOH/NCC films in distilled water and in an acidic solution

cellulose content the rate of water solubility also increase. Rate of water solubility for the pure $\mathrm{PVOH}$ was slower than the NCC modified PVOH composites. The 30/70 weight percent of $\mathrm{PVOH} / \mathrm{NCC}$ showed higher solubility rate, which indicated $60 \%$ for both of in water and acidic media [14]. For other weight ratio of $\mathrm{PVOH} / \mathrm{NCC}$ the solubility rate in water is higher than in acid because the concentration of acid is higher than of water.

\section{CONCLUSION}

Biodegradation rate of pure $\mathrm{PVOH}$ is slower than NCC modified PVOH composite. In case of enzyme, soil and compost the rate of degradation of the composite is increase with increasing the percentage of NCC content in the composite. The rate of water absorption in water and acidic media also depend on the NCC content in the composite. PVOH/NCC composites were more soluble in the distilled water medium relative to the acidic solution. From the surface study of the composite, it can be summarize that the dispersion of NCC in $70 / 30$ of $\mathrm{PVOH} / \mathrm{NCC}$ matrix showed better than other ratios. So this research shows that the biodegradation of the composite depends on the percentage of NCC. 


\section{COMPETING INTERESTS}

Authors have declared that no competing interests exist.

\section{REFERENCES}

1. Yang JH, Park J, Kim D, Lee D. Effects of calcium carbonate as the expanding inhibitor on the structural and mechanical properties of expanded starch/polyvinyl alcohol blends. Journal of Applied Polymer Science. 2004;93(4):1762-8.

2. Ching $Y C$, Rahman A, Ching KY, Sukiman NL, Cheng HC. Preparation and characterization of polyvinyl alcohol-based composite reinforced with nanocellulose and nanosilica. BioResources. 2015;10(2): 3364-77.

3. Guohua Z, Ya L, Cuilan F, Min Z, Caiqiong $Z$, Zongdao C. Water resistance, mechanical properties and biodegradability of methylated-cornstarch/poly (vinyl alcohol) blend film. Polymer Degradation and Stability. 2006;91(4):703-11.

4. Rahman A, Ching YC, Ching KY, Awanis $\mathrm{N}$, Chakraborty AK, Chuah $\mathrm{CH}$, Liou NS. Surface modification of natural fiber using $\mathrm{Bi} 2 \mathrm{O} 3 / \mathrm{TiO} 2$ composite for photocatalytic self-cleaning. BioResources. 2015;10(4): 7405-18.

5. Tang $\mathrm{S}$, Zou $\mathrm{P}$, Xiong $\mathrm{H}$, Tang $\mathrm{H}$. Effect of nano-SiO 2 on the performance of starch/polyvinyl alcohol blend films. Carbohydrate polymers. 2008;72(3):521-6.

6. Yun YH, Wee YJ, Byun HS, Yoon SD. Biodegradability of chemically modified starch (RS4)/PVA blend films: Part 2. Journal of Polymers and the Environment. 2008;16(1):12-8.

7. Jang BC, Huh SY, Jang JG, Bae YC. Mechanical properties and morphology of the modified HDPE/starch reactive blend. Journal of Applied Polymer Science. 2001; 82(13):3313-20.

8. Funke U, Bergthaller $W$, Lindhauer MG. Processing and characterization of biodegradable products based on starch. Polymer Degradation and Stability. 1998; 59(1-3):293-6.

9. Tuovinen $\mathrm{L}$, Peltonen $\mathrm{S}$, Liikola $\mathrm{M}$, Hotakainen M, Lahtela-Kakkonen M, Poso $A$, Järvinen $K$. Drug release from starchacetate microparticles and films with and without incorporated a-amylase. Biomaterials. 2004;25(18):4355-62.

10. Saba N, Mohammad F, Pervaiz M, Jawaid M, Alothman OY, Sain M. Mechanical, morphological and structural properties of cellulose nanofibers reinforced epoxy composites. International Journal of Biological Macromolecules; 2017.

11. Zhang $\mathrm{H}$, Ye G, Wei Y, Li X, Zhang A, Xie $\mathrm{J}$. Enhanced enzymatic hydrolysis of sugarcane bagasse with ferric chloride pretreatment and surfactant. Bioresource Technology; 2017.

12. Han $B$, Zhang $M$, Zhao D. In-situ degradation of soil-sorbed $17 \beta$-estradiol using carboxymethyl cellulose stabilized manganese oxide nanoparticles: Column studies. Environmental Pollution; 2017.

13. Boonmahitthisud A, Nakajima L, Nguyen KD, Kobayashi T. Composite effect of silica nanoparticle on the mechanical properties of cellulose-based hydrogels derived from cottonseed hulls. Journal of Applied Polymer Science. 2017;134(10).

14. Roy A, Hickner MA, Lee HS, Glass T, Paul M, Badami A, Riffle JS, McGrath JE. States of water in proton exchange membranes: Part A-Influence of chemical structure and composition. Polymer. 2017; 111:297-306.

(c) 2017 Islam et al.; This is an Open Access article distributed under the terms of the Creative Commons Attribution License (http://creativecommons.org/licenses/by/4.0), which permits unrestricted use, distribution, and reproduction in any medium, provided the original work is properly cited.

Peer-review history:

The peer review history for this paper can be accessed here: http://sciencedomain.org/review-history/19524 